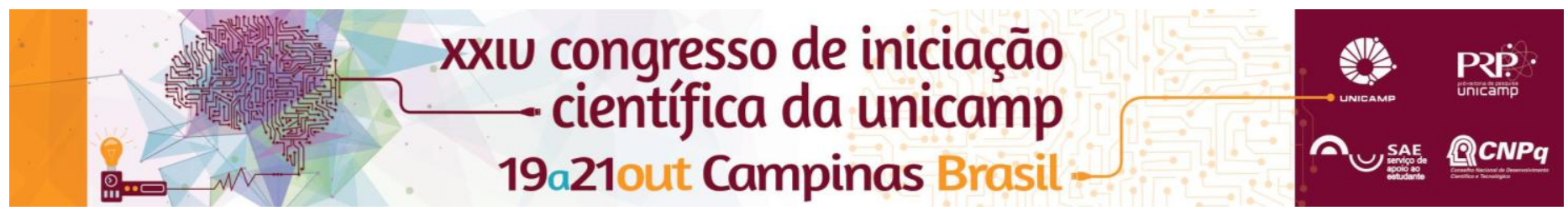

\title{
Ensaio de propagação ondas de ultrassom em peças de sistemas de contenção de encostas
}

\author{
Gabriela M. Cesar*, Cinthya Bertoldo.
}

\section{Resumo}

O Lock and Load é um sistema de contenção de encosta construído por módulos de concreto armado dimensionados para suportar elevadas cargas de compactação junto à face. O conjunto tem sido largamente utilizado, porém não há metodologia de acompanhamento da qualidade das peças (placas e contraforte) após a desmoldagem ou após a instalação. Sendo assim, essa pesquisa tem como objetivo avaliar resultados de ensaios de ultrassom, realizados de forma direta e indireta, em peças do sistema Lock and Load, visando verificar a viabilidade de utilização deste ensaio no acompanhamento e na inspeção deste sistema de contenção. Os resultados da pesquisa indicaram a viabilidade da utilização da técnica de ultrassom como ferramenta de acompanhamento e de inspeção do sistema de contenção de encostas.

\section{Palavras-chave:}

Concreto, propagação de onda superficial, propagação de onda longitudinal.

\section{Introdução}

O Lock and Load é um sistema de contenção de encosta construídos por módulos de concreto armado dimensionados para suportar elevadas cargas de compactação junto à face. O sistema é formado pela união de dois elementos, um painel e um contraforte, que podem ser pré-fabricados ou fabricados na própria obra. O conjunto tem sido largamente utilizado, porém não há metodologia de acompanhamento da qualidade das peças (placas e contraforte) após a desmoldagem ou após a instalação. O ultrassom é reconhecido como ferramenta adequada para a classificação do concreto e para a inspeção de estruturas de concreto armado. A medição direta de ultrassom é, em geral, a que tem resultados melhores correlações com as propriedades mecânicas, mas nem sempre pode ser realizada in loco, já que para isso é necessário que se tenha acesso à duas faces paralelas. Sendo assim, o objetivo dessa pesquisa é avaliar resultados de ensaios de ultrassom, realizados de forma direta e indireta, em peças do sistema Lock and Load, visando verificar a viabilidade de utilização deste ensaio no acompanhamento e na inspeção deste sistema de contenção.

\section{Resultados e Discussão}

Tanto as placas como o contraforte do sistema Lock and Load foram ensaiados de forma direta com diferentes frequências de transdutores $(25,45$ e $80 \mathrm{kHz})$ e apenas as placas foram ensaiadas de forma indireta com transdutores de $45 \mathrm{kHz}$ (Figura 1).

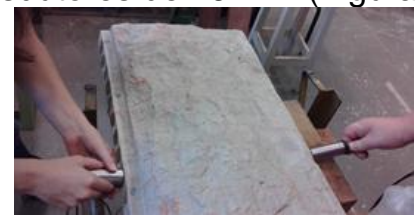

a

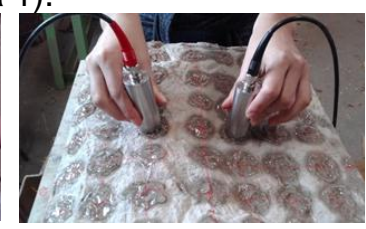

b
Figura 1. Ensaio de ultrassom sendo realizado de forma direta (a) e de forma indireta (b) nas placas do sistema. Considerando o ensaio direto realizado nas 5 placas e nas duas direções (longitudinal e transversal), a média da velocidade de ultrassom foi de $3674 \mathrm{~m} . \mathrm{s}^{-1}, 3755 \mathrm{~m} . \mathrm{s}^{-1}$ e $3662 \mathrm{~m} . \mathrm{s}^{-1}$ para as frequências de 25,45 e $80 \mathrm{kHz}$, respectivamente. Os resultados estatísticos de comparação de médias mostraram haver diferença estatisticamente significativa $(P$-valor $<0,05)$ para as leituras realizadas com o transdutor de $45 \mathrm{kHz}$ quando comparado com as leituras realizadas com os transdutores de $25 \mathrm{khz}$ e de $80 \mathrm{kHz}$.

Os ensaios superficiais realizados com transdutores planos e exponenciais de $45 \mathrm{kHz}$ apresentaram comportamento quase que linear de variação da velocidade com 0 aumento da distância entre os transdutores. Quando o ensaio superficial foi realizado com o transdutor exponencial, porém com a realização de um pequeno orifício na placa para a inserção da ponta do transdutor, a velocidade tendeu a diminuir até a distância de 0,4 m entre transdutores e a partir dessa distância tendeu à um valor constante.

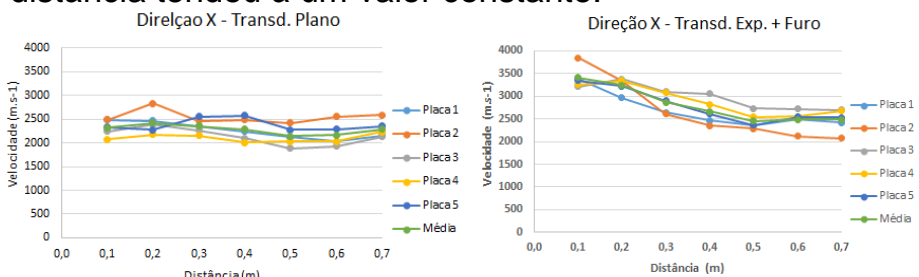

Figura 2. Variação da velocidade superficial com a distância entre transdutores.

Os resultados dos ensaios superficiais nas placas, a partir da distância entre os transdutores que a velocidade apresentou pequena variação, representaram uma porcentagem do valor da velocidade obtida de forma direta, que variou de 60 a $68 \%$, dependendo do tipo de transdutor utilizado (plano e exponencial) e das condições do ensaio (placa com ou sem furo).

\section{Conclusões}

Os resultados dessa pesquisa mostraram que a velocidade de ultrassom, obtida de forma indireta, representa uma porcentagem, que variou de 60 a $68 \%$, do ensaio de ultrassom quando realizado de forma direta, o que indica a viabilidade de utilização da técnica como ferramenta para acompanhamento e inspeção do sistema de contenção de encostas.

\section{Agradecimentos}

Ao SAE pela bolsa de Iniciação Científica, à FEAGRI e ao LabEND.

VERMA, S. K.; BHADAURIA, S. S.; AKHTAR, S. Review Article: Review of Nondestructive Testing Methods for Condition Monitoring of Concrete Structures. Journal of Construction Engineering, p. 1-11, 2013. 